\title{
РАСПРЕДЕЛЕНИЕ РИСКОВ В ПРОЕКТАХ ГОСУДАРСТВЕННО-ЧАСТНОГО ПАРТНЕРСТВА: СОВРЕМЕННЫЕ ВЫЗОВЫ И ПУТИ РЕШЕНИЯ
}

\section{(c) 2020 Васин Сергей Григорьевич}

кандидат экономических наук, доцент Базовой кафедры Федеральной антимонопольной службы Российский экономический университет имени Г. В. Плеханова, Россия, Москва E-mail:Vasin.SG@rea.ru

\section{(c) 2020 Ахматова Джамиля Руслановна}

Факультет экономики и права, 4 курс

Российский экономический университет имени Г. В. Плеханова, Россия, Москва

E-mail: akhmatova.dzhamilya@mail.ru

\section{(C) 2020 Кабакова Виктория Михайловна}

Факультет экономики и права, 4 курс

Российский экономический университет имени Г. В. Плеханова, Россия, Москва

E-mail: vkabakova@list.ru

\section{(c) 2020 Чикаев Руслан Александрович}

Факультет экономики и права, 4 курс

Российский экономический университет имени Г. В.Плеханова, Россия, Москва

E-mail: ruslan2233@hotmail.com

В статье проведен анализ нормативно-правовой базы, научных трудов отечественных и зарубежных практиков. Авторами выделяются основные проблемы распределения ответственности и рисков между публичной и частной стороной, а также предлагаются пути решения данной проблемы.

С целью формирования понимания, как распределяются риски в проектах ГЧП и разработки рекомендаций более справедливого и рационального их распределения, в рамках данной научной статьи проводится исследование, анализ и синтез действующих нормативно-правовых источников, учебной литературы и практики реализации проектов государственно-частного партнёрства; распределения рисков в соглашениях о ГЧП.

Комплексное авторское исследование проблем распределения рисков в проектах ГЧП и разработка рекомендаций более справедливого и рационального их распределения являются основной целью и ключевыми задачами настоящей статьи. Выявленные проблемы распределения рисков в проектах-ГЧП сподвигли авторов данной статьи к разработке рекомендаций по их минимизации, а также более справедливому их распределению между участниками партнёрств для повышения эффективности и значимости всего института ГЧП в России.

Решение наиболее актуальной на сегодняшний день проблемы в государственно-частном партнерстве - распределения рисков, позволит значительно увеличить количество проектов ГЧП, привлечь инвестиции, а также повысить эффективность взаимодействия частной и публичной стороны.

Ключевые слова: государственно-частное партнерство, риск, распределение рисков, ГЧП-проект, закупки, контракт, механизм разрешения споров, справедливое распределение рисков и обязательств, публичный партнёр, частный партнёр.

Вопрос распределения рисков в проектах государственно-частного партнерства (ГЧП) особенно остро встаёт в последнее время как у потенциального частного партнёра, так и у государственных (муниципальных) органов власти, реализующих данные проекты. Справед- ливое распределение рисков и обязательств между сторонами соглашения о государственночастном партнёрстве закреплено законодательно (№ 224-Ф3 [1]). На практике же распределение риска между публичной и частной стороной не всегда выглядит справедливо и логично. Не- 
разрешенным остается вопрос распределения рисков между сторонами ГЧП-проектов. Именно данная проблема определяет актуальность настоящего исследования и определяет его цель.

Основной задачей настоящей работы является комплексное авторское исследование проблемы распределения рисков в проектах ГЧП и разработка рекомендаций более справедливого и рационального их распределения.

В отличие от системы госзакупок [2], где все риски берёт на себя государственный (муниципальный) заказчик и выступает при этом единственным финансирующим источником, а при закрытии контракта и собственником созданного объекта (продукции, услуги), при реализации проектов ГЧП, в зависимости от форм и моделей ГЧП, распределение каждого из типов рисков - обсуждаемый вопрос, который занимает достаточно много времени на этапах доконкурсного обсуждения потенциального проекта ГЧП, проведения конкурса по проекту ГЧП, и даже в процессе его реализации.

В процессе исследования проблемы распределения рисков ГЧП используются методы логического анализа и синтеза полученной информации, интерпретации и корректировки зарубежной практики для применения данного опыта в России.

Проведенный анализ позволяет выделить наиболее актуальные проблемы в распределении рисков в проектах ГЧП:

1. Невозможность точного прогнозирования рисков в проектах ГЧП;

2. Сложность выбора модели взаимодействия публичного и частного партнеров;

3. Нецелесообразное распределение рисков между публичным и частным партнерами.

\section{Научная новизна:}

Для решения проблем распределения рисков ГЧП авторами предлагается создание цифрового реестра проектов ГЧП с возможностью построения прогнозных сценариев с учетом усредненных тенденций, также были даны другие рекомендации по оптимальному распределению рисков в проектах ГЧП в России.

Теоретическая значимость работы заключается в систематизации информации по распределению рисков в проектах-ГЧП на различных этапах, формулировании методов управления различными типами рисков.

Практическая значимость работы состоит в выявлении проблем распределения рисков в проектах-ГЧП, а также разработке рекомендаций по их устранению.

В Федеральном законе № 224-Ф3 «О государственно-частном партнерстве, муниципально-частном партнерстве в Российской Федерации и внесении изменений в отдельные законодательные акты Российской Федерации» среди основных принципов государственночастного партнерства выделяется: «справедливое распределение рисков и обязательств между сторонами соглашения» [1]. Из данного принципа следует, что публичный партнер берет на себя часть рисков и гарантирует частной стороне определенную компенсацию убытков.

В соответствии с российским законодательством существуют различные типы проектов ГЧП, которые предполагают различное распределение рисков между публичной и частной стороной. По степени соотношения риска между публичной и частной стороной их можно разделить на модель публичной закупки, концессию, формы квази-ГЧП, корпоративное ГЧП и приватизацию (рис. 1).

Рассмотрим более подробно эти модели и формы ГЧП.

Модель публичной закупки предполагает создание инфраструктурных объектов частной стороной за счет бюджетных средств, т.е. все риски по проекту несет публичный сектор.

По концессионному соглашению концессионер (частная сторона) создает или реконструирует объект соглашения, а концедент (публичная сторона) предоставляет права владения и пользования объектом концессионеру на определенный срок.

Формы квази-ГЧП не всегда устанавливают переход прав собственности на объект к частной стороне, но риски распределяются достаточно равномерно.

Корпоративное ГЧП влечет полную ответственность частного сектора за качество предоставления услуг населению и управление объекTOM.

Приватизация заключается в передаче прав собственности, а вместе с ней и всех рисков частному партнеру.

Таким образом, необходимо особое внимание уделять выбору типа проекта ГЧП. Практика свидетельствует о том, что одна сторона всегда стремится переложить риски на другую сторону. Однако основное правило распределения рисков между партнерами - каждый риск по про- 


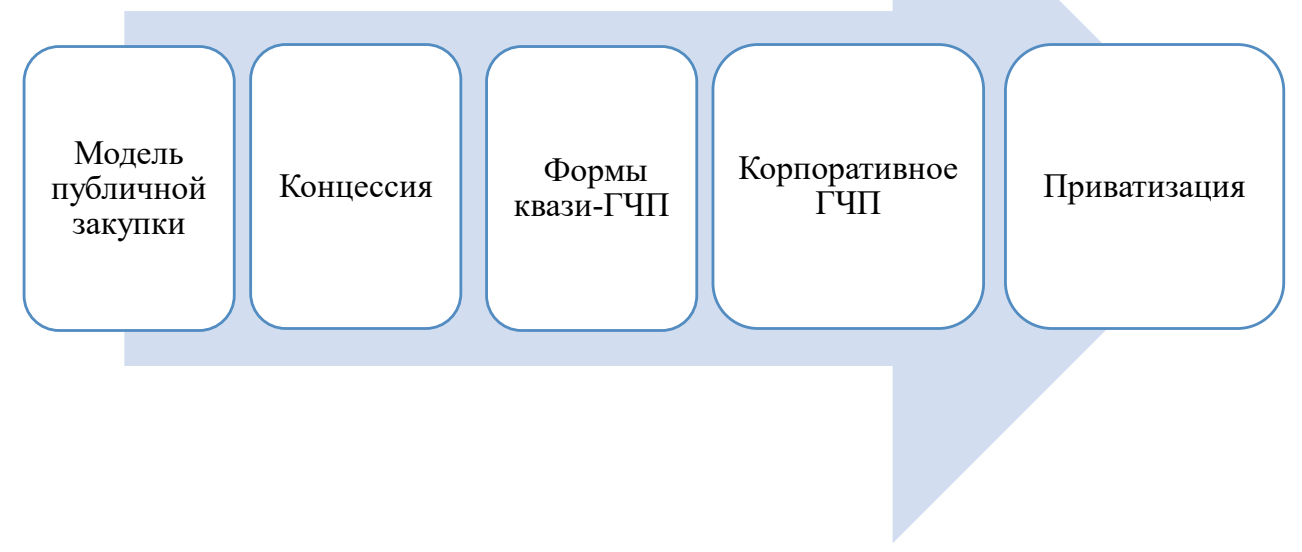

Puc. 1. Распределение рисков по типу проекта ГЧП [3, с. 264].

екту несет та сторона, которая может управлять им наилучшим образом. При этом рыночными рисками наиболее эффективно способен управлять частный партнер, а законодательными и политическими - публичный [4, с. 132].

Наилучшее распределение рисков проектов ГЧП по их типам между публичной и частной стороной представлено в табл. 1.

Помимо оптимального распределения рисков важно уметь ими управлять. В связи с этим можно выделить несколько методов управления рисками [3, с. 278].

Во-первых, избегание. Этот метод применяется тогда, когда вероятность риска слишком высока. В этом случае проект не реализуется. Например, автотрассу не будут прокладывать рядом с местом ведения боевых действий, т.к. велик риск ущерба созданной инфраструктуре и здоровью людей, исполняющих проект.

Во-вторых, предупреждение. Данный метод предполагает исключение источника риска или выбор альтернативного пути. Так, если возможно провести автотрассу по краю леса, а не через сам лес, то можно исключить возможность возникновения экологической проблемы, т.е. нейтрализовать экологический риск.

В-третьих, снижение. Снижение предполагает внесение изменений в структуру проекта с целью снижения роли рискованной деятельности. Следуя данному методу, можно взять кредит под более высокий процент, но в надежном банке.
В-четвертых, передача. Иначе этот метод можно назвать аутсорсингом, т.е. риски передаются сторонней организации. Так, например, функции по техобслуживанию объекта может быть выгодно передать специализированной организации.

B-пятых, страхование - один из наиболее часто используемых методов управления рисками в сфере ГЧП. Страхование предполагает перенос ответственности в случае реализации риска на страховую компанию. Чаще всего в проектах ГЧП предусмотрено страхование риска возникновения пожара.

В-шестых, принятие. Принятие возможно только тогда, когда риск наносит небольшой ущерб реализации проекта. Так, при строительстве объекта можно закупить немного больше материалов, чем это необходимо на случай, если часть материалов окажется бракованной.

Для выбора конкретного метода необходимо заранее спрогнозировать возможный ущерб и оценить рациональность применяемых мер по снижению или уходу от риска.

К тому же существует законодательно утвержденные допустимые значения вероятных отклонений, учитываемые при расчете объема принимаемых публичным партнером обязательств в случае возникновения рисков при реализации проекта ГЧП. Значения допустимых отклонений сумм обязательств в случае возникновения рисков проектов ГЧП представлены в табл. 2. 
Таблица 1. Распределение рисков проекта ГЧП между публичной и частной стороной по их типу [5].

\begin{tabular}{|c|c|c|}
\hline Тип риска & $\begin{array}{c}\text { Публичная } \\
\text { сторона }\end{array}$ & $\begin{array}{l}\text { Частная } \\
\text { сторона }\end{array}$ \\
\hline $\begin{array}{l}\text { 1. Политические риски: } \\
\text { - экспроприация; } \\
\text { - общая модификация в законах и налоговой системе; } \\
\text { - специфическая модификация в законах и налоговой системе; } \\
\text { - политические события; } \\
\text { - расторжение концессии государством; } \\
\text { - ограничение конвертируемости валюты. }\end{array}$ & $\begin{array}{l}\mathrm{V} \\
\mathrm{V} \\
\mathrm{V} \\
\mathrm{V} \\
\mathrm{V}\end{array}$ & V \\
\hline $\begin{array}{l}\text { 2. Риски завершения строительства: } \\
\text { - приобретение земли; } \\
\text { - превышение затрат (исключающих изменение в проекте); } \\
\text { - превышение затрат (изменение в проекте); } \\
\text { - увеличение финансовых затрат; } \\
\text { - риски в спецификации и качестве работ; } \\
\text { - риск задержек во времени из-за административных процедур; } \\
\text { - убытки, понесенные при выполнении работ; } \\
\text { - банкротство компании-концессионера. }\end{array}$ & $\begin{array}{l}\mathrm{V} \\
\mathrm{V} \\
\mathrm{V} \\
\mathrm{V} \\
\mathrm{V}\end{array}$ & $\begin{array}{l}\mathrm{V} \\
\mathrm{V} \\
\mathrm{V} \\
\mathrm{V} \\
\mathrm{V} \\
\mathrm{V}\end{array}$ \\
\hline $\begin{array}{l}\text { 3. Эксплутационные риски: } \\
\text { - воздействие на окружающую среду; } \\
\text { - форс-мажорные события; } \\
\text { - технологический риск; } \\
\text { - превышение затрат; } \\
\text { - изменения в спецификации. }\end{array}$ & $\begin{array}{l}\mathrm{V} \\
\mathrm{V}\end{array}$ & $\begin{array}{l}\text { V } \\
\text { V } \\
\text { V } \\
\text { V }\end{array}$ \\
\hline $\begin{array}{l}\text { 4. Коммерческие риски: } \\
\text { - падение в трафике; } \\
\text { - политика управления ценой; } \\
\text { - другие доходы; } \\
\text { - строительство конкурирующих объектов. }\end{array}$ & $\begin{array}{l}\mathrm{V} \\
\mathrm{V} \\
\mathrm{V}\end{array}$ & $\begin{array}{l}\mathrm{V} \\
\mathrm{V} \\
\mathrm{V}\end{array}$ \\
\hline $\begin{array}{l}\text { 5. Финансовые риски: } \\
\text { - инфляция; } \\
\text { - процентные ставки; } \\
\text { - валютные курсы. }\end{array}$ & $\begin{array}{l}\mathrm{V} \\
\mathrm{V}\end{array}$ & $\begin{array}{l}\mathrm{V} \\
\mathrm{V} \\
\mathrm{V}\end{array}$ \\
\hline $\begin{array}{l}\text { 6. Правовые риски: } \\
\text { - разрешения и лицензии; } \\
\text { - судебный процесс. }\end{array}$ & $\begin{array}{l}\text { V } \\
\text { V }\end{array}$ & $\begin{array}{l}\text { V } \\
\text { V }\end{array}$ \\
\hline
\end{tabular}

Таблица 2. Допустимые отклонения суммы обязательств в случае возникновения рисков [6].

\begin{tabular}{|c|l|c|}
\hline № & \multicolumn{1}{|c|}{ Виды рисков } & Допустимое отклонение, \% \\
\hline 1 & Риски создания объекта & от 5 до 12 \\
\hline 2 & Риски проектирования и подготовительных мероприятий & от 7 до 15 \\
\hline 3 & Риски эксплуатации объекта & от 15 до 25 \\
\hline 4 & Риски получения доходов от использования объекта & от 20 до 40 \\
\hline 5 & Прочие риски & от 5 до 10 \\
\hline
\end{tabular}


Наибольшее допустимое отклонение возможно в случае рисков получения доходов от использования объекта, возможно, ввиду того, что это не приведет к полному закрытию проекта, а также данные риски достаточно сложно определить с точки зрения прогнозирования, т.к. спрос на объекты ГЧП колеблется в условиях рыночной экономики.

Еще одним важным вопросом в распределении рисков является тип взаимодействия между публичной и частной стороной. Многие рассматривают государственно-частное партнерство как альтернативу государственным закупкам. Вопрос выбора формы взаимодействия государства и частного партнера напрямую связан с распределением рисков. Так, согласно Федеральному закону «О контрактной системе в сфере закупок товаров, работ, услуг для обеспечения государственных и муниципальных нужд» от 05.04.2013 N 44-Ф3, государство берет на себя риски качества проектирования, строительства и эксплуатации [2]. В ГЧП же устанавливаются технико-экономические показатели, по которым контролируется качество оказания услуг, однако вопрос распределения рисков между частной и публичной стороной не урегулирован [7].

На рисунке 2 можно наблюдать уровень рисков на стадии строительства. Стоит отметить, что на данном этапе реализации проекта стороны несут наибольшие риски. Сопоставляя риски, связанные с государственным заказом и ГЧП, можно наблюдать, что риски в рамках закона № 44-Ф3 в 4,5 раз превышают риски ГЧП, так в 2017 г. на этапе строительства риски государственного заказа составили 1,8 миллиона рублей, в то время как в рамках ГЧП - всего 420 тысяч рублей [8].

Стоит рассмотреть наиболее длительную стадию - стадию эксплуатации (рис. 3). На данном этапе также наблюдается ярко-выраженная тенденция преобладания рисков государственного заказа над ГЧП в более чем 3 раза.

Рисунки 2 и 3 свидетельствуют о превышении рисков госзаказа над ГЧП, однако важно отметить, что вероятность наступления данных рисков не зависит от формы взаимодействия публичного и частного партнера.

Для выбора наиболее оптимальной формы реализации проекта государство использует модель сравнительного преимущества (PSC), кото-

\section{Риски на стадии строительства}

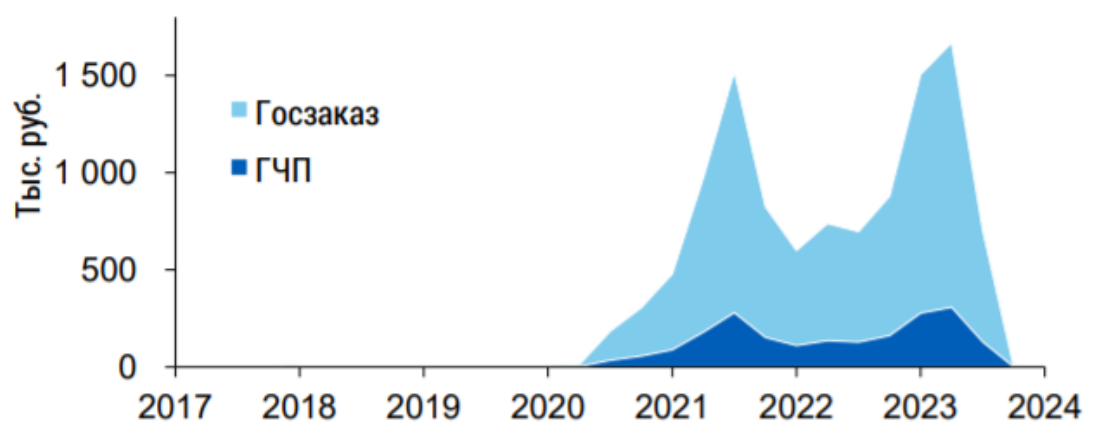

Рис. 2. Риски на стадии строительства в рамках законов № 44-Ф3 и № 224-Ф3 [8].

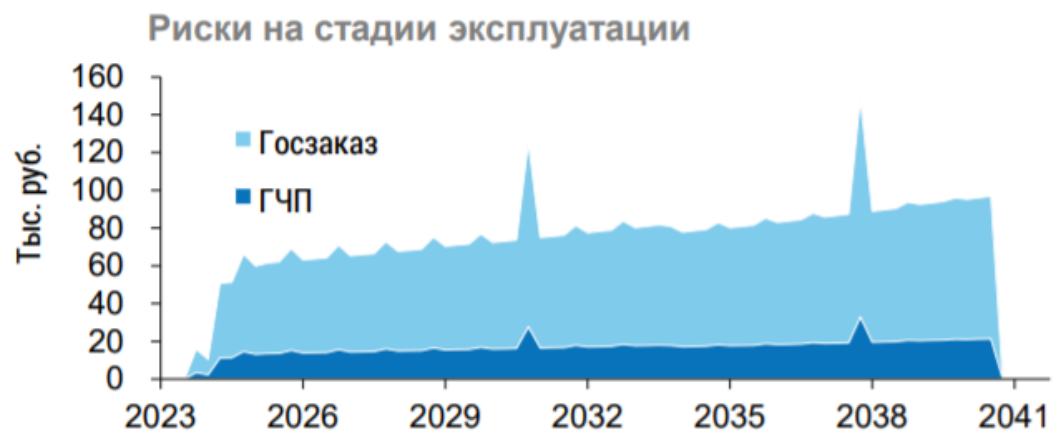

Рис. 3. Риски на стадии эксплуатации в рамках законов № 44-Ф3 и № 224-Ф3 [8]. 
рая подразумевает расчет цены аналогичного проекта через прямое бюджетное финансирование. Методика оценки сравнительного преимущества утверждена Министерством экономического развития в Приказе № 894 от 30 ноября 2015 года [3]. Из данной методики следует, что в государственном заказе все риски ложатся на публичного партнера. На рисунке 4 представлено сопоставление стоимости проекта для государства в рамках государственного заказа и ГЧП. Как видно из графика, стоимость проекта по закону № 44-Ф3 превышает стоимость в рамках ГЧП на 30,2\%. Существенное различие в стоимости проекта составляют итак называемые «сохраняемые риски», которые являются результатом количественной оценки [8].

Обращаясь к международной практике выбора оптимальной формы реализации проекта, стоит отметить, что в некоторых странах (таких как Чили) используется простая оценка соотношения бюджетных затрат на реализацию проекта в рамках ГЧП и с помощью государственных закупок. Такая практика недостаточно эффективна в современных реалиях, поэтому большинство стран (Канада, Южная Корея и др.) сравнивает бюджетные издержки отдельно по каждому этапу с учетом рисков. Данную практику усовершенствовали еще несколько стран, в том числе Франция, которые помимо учета рисков в ходе анализа, также оценивают социально-экономическую выгоду между моде- лями государственных закупок и ГЧП [7].

Проведенный анализ позволяет выделить наиболее актуальные проблемы в распределении рисков:

1. Невозможность точного прогнозирования рисков;

2. Сложность выбора модели взаимодействия публичного и частного партнеров;

3. Нецелесообразное распределение рисков между публичным и частным партнерами.

Для решения первой проблемы авторами предлагается создание цифрового реестра проектов ГЧП с возможностью построения прогнозных сценариев с учетом усредненных тенденций.

Вторая проблема может быть решена с помощью внедрения французской модели, которая имеет большой потенциал для адаптации к российским реалиям.

Для нивелирования третьей проблемы авторами предлагается закрепление в федеральном законе № 224-Ф3 распределения типов рисков между сторонами проектов ГЧП, которое подробно представлено в таблице 1 .

Таким образом, решение наиболее актуальной на сегодняшний день проблемы в государственно-частном партнерстве - распределения рисков, позволит значительно увеличить количество проектов ГЧП, привлечь инвестиции, а также повысить эффективность взаимодействия частной и публичной стороны.

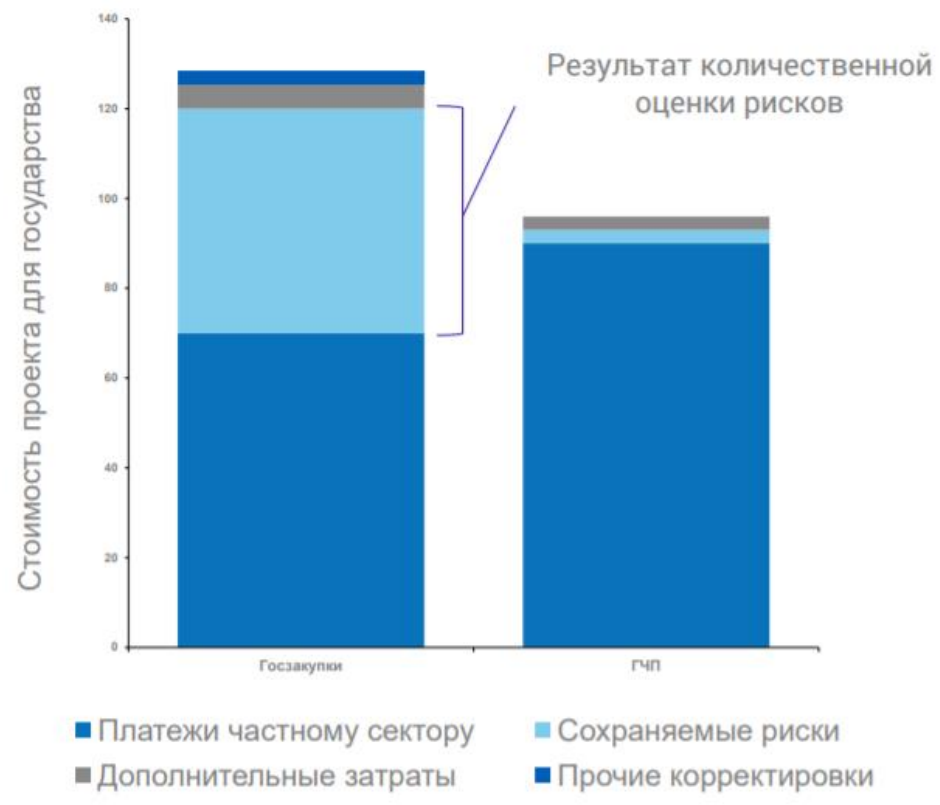

Puc. 4. Стоимость проекта для государства [8] 


\section{Заключение}

Вопрос распределения рисков в проектах государственно-частного партнерства особенно остро встаёт в последнее время как у потенциального частного партнёра, так и у государственных (муниципальных) органов власти. При этом справедливое распределение рисков и обязательств между сторонами соглашения о государственно-частном партнёрстве закреплено законодательно. В статье проведен анализ нормативно-правовой базы, научных трудов отечественных и зарубежных практиков. Авторами выделяются основные проблемы распределения ответственности и рисков между публичной и частной стороной, а также предлагаются пути решения данной проблемы.

Комплексное авторское исследование проблемы распределения рисков в проектах ГЧП и разработка рекомендаций более справедливого и рационального их распределения.

В процессе исследования проблемы распределения рисков ГЧП использовались методы логического анализа и синтеза полученной информации, интерпретации и корректировки зарубежной практики для применения данного опыта в России.

Проведенный анализ позволяет выделить наиболее актуальные проблемы в распределении рисков в проектах ГЧП:

1. Невозможность точного прогнозирования рисков в проектах ГЧП;

2. Сложность выбора модели взаимодействия публичного и частного партнеров;

3. Нецелесообразное распределение рисков между публичным и частным партнерами.

Для решения проблем распределения рисков ГЧП авторами предлагается создание цифрового реестра проектов ГЧП с возможностью построения прогнозных сценариев с учетом усредненных тенденций; даны другие рекомендации по оптимальному распределению рисков в проектах ГЧП в России.

Решение наиболее актуальной на сегодняшний день проблемы в государственно-частном партнерстве - распределения рисков, позволит значительно увеличить количество проектов ГЧП, привлечь инвестиции, а также повысить эффективность взаимодействия частной и публичной стороны.

\section{Библиографический список}

1. Федеральный закон «О государственно-частном партнерстве, муниципально-частном партнерстве в Российской Федерации и внесении изменений в отдельные законодательные акты Российской Федерации» от 13.07.2015 N 224-ФЗ URL: http://www.consultant.ru/document/cons_doc_LAW_182660/ (дата обращения: 27.12.2019).

2. Федеральный закон «О контрактной системе в сфере закупок товаров, работ, услуг для обеспечения государственных и муниципальных нужд» от 05.04.2013 N 44-Ф3 URL: http://www.consultant.ru/document/ cons_doc_LAW_144624/(дата обращения: 27.12.2019).

3. Борщевский Г.А. Государственно-частное партнерство: учебник и практикум для вузов. - 2-е изд., испр. и доп.- Москва: Издательство Юрайт, 2019.- 412 с.- URL: https://www.biblio-online.ru/bcode/433239/p.265 (дата обращения: 23.12.2019).

4. Ткаченко Н.И. Государственно-частное партнерство: учебное пособие для бакалавриата и магистратуры.Москва: Издательство Юрайт, 2019.- 188 с.- URL: https://www.biblio-online.ru/bcode/434038/p.134 (дата обращения: 23.12.2019).

5. Андерсен А.П. О юридических аспектах минимизации рисков в проектах государственно-частного партнерства // Социально-политические науки. - № 1._ 2016.- c. 84-88. - URL: https://cyberleninka.ru/article/ n/o-yuridicheskih-aspektah-minimizatsii-riskov-v-proektah-gosudarstvenno-chastnogo-partnerstva (дата обращения: 06.02.2020).

6. Приказ Минэкономразвития России от 30.11.2015 N 894 «Об утверждении Методики оценки эффективности проекта государственно-частного партнерства, проекта муниципально-частного партнерства и определения их сравнительного преимущества» URL: http://www.consultant.ru/document/cons_doc_LAW_192148/ (дата обращения: 27.12.2019).

7. Экспертный релиз: обоснование эффективности применения механизмов ГЧП // Национальный Центр ГЧП URL: http://pppcenter.ru/assets/docs/reliz-1-17_ocen.pdf (дата обращения: 27.12.2019).

8. Управление рисками в проектах ГЧП: от идентификации до оценки и выработке мер по снижению последствий // Первая концессионная корпорация URL: https://mineconom74.ru/sites/default/files/imceFiles/ user-318/upravlenie_riskami.pdf (дата обращения: 27.12.2019). 